\title{
Recurrent Sarcoma of the Extremity
}

National Cancer Institute

\section{Source}

National Cancer Institute. Recurrent Sarcoma of the Extremity. NCI Thesaurus. Code C155648.

A sarcoma of the soft tissues or bones of the upper or lower extremity that has recurred after a period of remission. 